\title{
Menores, bullying y suicidio. \\ Un análisis de caso a través de los medios digitales de referencia en España
}

\author{
Recibido: 25 de julio de 2018 \\ Aceptado: 13 de agosto de 2018 \\ Publicado: 28 de noviembre de 2018
}

\author{
Ander Pérez-Virtus \\ andervirtus@gmail.com \\ Ainara Larrondo-Ureta \\ ainara.larrondo@ehu.es
}

Universidad del País Vasco (España)

Resumen: En los casos de cobertura informativa del acoso escolar o bullying (Olweus, 1998; Mason, 2008) se espera de los medios de comunicación una especial atención a las normas de la deontología periodística, puesto que este tipo de coberturas suman infancia, violencia y, en algunos casos, tristemente, suicidio (Herrera et al., 2015). Aunque los medios de comunicación han evitado tradicionalmente realizar este tipo de coberturas, dando lugar a un silencio informativo que responde a su temor a un posible "efecto de imitación" (Philips, 1974), resulta un hecho que este tipo de informaciones encuentran cada vez más lugar en los medios, ante el aumento del interés público y social por la problemática del bullying. En vista de la escasez de investigaciones sobre el tipo de tratamiento mediático de este tipo de casos (Müller, 2011), este artículo examina códigos deontológicos y la cobertura mediática en España de tres casos de menores suicidados a causa del acoso escolar. Los resultados del análisis arrojan luz sobre las posibles consecuencias de la publicación de este tipo de contenido informativo y sobre cómo mejorar su tratamiento evitando factores de riesgo.

Palabras clave: Bullying, cobertura mediática, suicidio, cibermedios.

Abstract: Media are supposed to pay special attention to the traditional journalistic ethical
norms in the cases of media coverage of bullying in schools (Olweus, 1998; Mason, 2008),
insofar as these combine childhood, violence and, in some unfortunate cases, suicide (Herrera
et al., 2015). Even if mass media have traditionally avoided these kind of coverage, giving 
rise to an informative silence that answers to its concern about a possible "imitation effect" (Philips, 1974), it is a fact that the topic has gained attention in the media sphere, probably due a growing public and social interest towards the bullying problem. Because of the scarce researches on media coverage of bullying in schools related to suicide (Müller, 2011), this paper examines the ethical codes and the media treatment of three significant cases in Spain. The results shed light on the consequences of releasing this kind of informative content and on the options to improve this kind of treatment avoiding risk factors.

Key words: Bullying, Media Coverage, Suicide, Online Media.

\section{Introducción}

Resulta un hecho que en los últimos tiempos han aumentado las informaciones en medios de comunicación sobre casos de acoso escolar o bullying y sobre las consecuencias de este fenómeno. Este interés responde a la alarma social generada en torno al acoso escolar, en parte, debido a las duras consecuencias que tiene en algunos casos, el suicidio. De hecho, los medios de comunicación cubren sucesos de suicidio de menores que se vinculan en un porcentaje muy alto al acoso escolar.

El acoso escolar o bullying hace referencia a situaciones de maltrato entre escolares que conlleva actos de violencia continuada (ya sea esta verbal, psicológica o física) guiada por un individuo o un grupo hacía una o varias personas, generalmente, con escasa capacidad de defensa: "Un alumno es agredido o se convierte en víctima cuando está expuesto, de forma repetida y durante un tiempo, a acciones negativas que lleva a cabo otro alumno o varios de ellos" (Olweus, 1998, p. 25). Cerezo (2002) indica que el acoso escolar suele ser, en la mayoría de casos, intencionado y generalmente se da hacía un compañero más débil que se convierte en víctima habitual, pudiendo durar semanas, meses o años.

Las investigaciones acerca del bullying comenzaron a despuntar en Noruega cuando los medios de comunicación publicaron, en el año 1982, la noticia del suicidio de tres adolescentes a causa del acoso escolar al que fueron sometidos. En España, el estudio de este fenómeno surge en la década de los noventa con la realización de diferentes estudios a nivel autonómico y nacional (Orte Socías, 2006, p. 29). Sin embargo, no fue hasta el año 2004 cuando los medios de comunicación publicaron el suicidio de Jokin Ceberio, creando un punto de inflexión y una alarma social en relación a los casos de acoso escolar en España.

Desde un enfoque psicológico, se habla del bullying cómo una forma de comportamiento agresivo caracterizado por un desequilibrio de poder entre el agresor y la víctima que puede tener un periodo prolongado. Además, no es un fenómeno interpersonal, sino grupal, ya que todos los compañeros actúan como observadores o animadores, por lo que los acosadores se sienten respaldados y la víctima indefensa (Gaviria, López \& Cuadrado, 2013, p. 403). Una de las principales funciones de los 
medios de comunicación es reflejar la realidad social, si bien en diferentes manuales periodísticos se recomienda la no divulgación de noticias acerca del suicidio, por el riesgo de imitación ${ }^{1}$.

Olmo \& García (2014) reflexionan sobre la problemática publicación del suicidio en los medios: "No es sencillo abordar el suicidio, pues es un acto complejo en el que se identifican tres elementos: ocurre una muerte, es ocasionada por la propia persona, y es intencionado" (p. 1151). Los mismos autores señalan la incongruencia de no tratar el suicidio en los medios con su labor de reflejar la realidad social. Cabría recordar aquí, brevemente, que los medios de comunicación evidencian una gran legitimidad social a partir de su poder para decidir qué asuntos llegarán a la ciudadanía y la opinión pública, lo que conlleva cierta capacidad y poder para influir sobre las conductas, creencias y actitudes de la sociedad.

La sociedad percibe ciertas temáticas más relevantes en proporción a la importancia que le otorgan los medios (McCombs \& Shaw, 1972). Dicho de otro modo, lo que no aparece en los medios no existe, como bien expresa la teoría de la agenda-setting: "La prensa no tiene mucho éxito en decir a la gente qué tiene que pensar pero sí lo tiene en decir a sus lectores sobre qué tienen que pensar" (Cohen, 1963, p. 13).

Esta idea se puede asociar con la invisibilización pública de sucesos sobre suicidios con el fin de evitar una alarma social y sus consecuencias. La imitación de la conducta suicida puede vincularse, asimismo, con otras teorías señeras del ámbito de la comunicación de masas, como la "teoría de la espiral del silencio" de Noelle-Neumann (1977), vinculada también al poder de los medios de comunicación para determinar la atención de la opinión pública sobre determinados temas.

Según los datos recogidos por los informes del Instituto Nacional de Estadística, INE (2017) de España, la tasa de suicidio se ha elevado en este país, siendo la quinta causa dentro de la clasificación de muerte por causa externa o natural. Los informes anuales del INE muestran cómo el número de suicidios se ha ido elevando desde el año 2005 hasta el 2016, siendo los últimos cuatro años los más llamativos en el crecimiento de la tasa. Según el INE (2017), el suicidio es la tercera causa de muerte entre adolescentes.

Olmo \& García (2014, p. 1150) definen el suicidio desde una perspectiva global tomando como partida la causa: "El suicidio se interpreta como un acto por el que se adopta una solución extrema ante una serie de problemas sociales, psicológicos y personales, que derivan de conflictos emocionales, familiares, sociales, económicos, de adaptación o por problemas de salud". El suicidio ha sido también definido por causas sociales y psicológicas que repercuten a

1 Este fue definido en la década de los setenta por Phillips (1974), quien acuñó la expresión "efecto Werther" para describir la sugestión de la conducta suicida. Phillips fue el primero en hacer un análisis cuantitativo sobre el papel de los medios de comunicación en el efecto de imitación de la conducta suicida. Según su estudio, realizado entre 1947 y 1968, la cantidad de suicidio imitado es proporcional a la cantidad, duración y tratamiento de las informaciones publicadas acerca del suicidio. 
los adolescentes en el centro escolar y fuera de este. En cuanto a los factores sociales se toman en cuenta, encontramos el estatus social, el rendimiento académico, las habilidades sociales, la relación entre iguales y el contexto familiar. Por otro lado, entre los factores psicológicos que repercuten en la ideación suicida en el caso de menores cabría destacar la personalidad, las técnicas de afrontamiento y la autoestima.

Con la llegada de la era digital, el bullying se ha extendido de espacio físico al virtual, abriendo su abanico a nuevas formas de acoso a través de la red: el cyberbullying. Según Willard (2004), las acciones más frecuentes del cyberbullying suelen ser el envío y/o la acción de colgar (sending \& posting) textos o imágenes dañinas en Internet. Podríamos relacionar el concepto de cyberbullying con la publicación de agresiones y acoso escolar de las víctimas en los medios digitales, puesto que la acción del acoso digital es trasmitir el contenido dañino por medios digitales de comunicación. Mason (2008, p. 323) describe esta nueva tendencia de acoso de la siguiente manera:

El cyberbullying se define como el uso de información y comunicación a través de la tecnología que un individuo o un grupo utiliza deliberadamente y de manera repetida para el acoso o amenaza hacia otro individuo o grupo mediante el envío o publicación de texto cruel y/o gráficas a través de los medios tecnológicos.

\section{Marco contextual: el tratamiento informativo del menor y el suicidio}

La Organización Mundial de la Salud (OMS) difundió en el año 1999 el programa SUPRE sobre prevención del suicidio. Mediante este programa se proponía también qué tratamiento informativo debían seguir los profesionales de la comunicación en relación al suicidio. La OMS (2000) señalaba como prácticas positivas las siguientes: a) trabajar estrechamente con autoridades de la salud en la presentación de los hechos, b) referirse al suicidio como un hecho logrado y no uno exitoso, $c$ ) resaltar las alternativas al suicidio, $d$ ) proporcionar información sobre líneas de ayuda y e) publicitar indicadores de riesgo o de señales de advertencia. En cuanto a las prácticas negativas a evitar, se indicaban las siguientes: a) no publicar fotografías o notas suicidas, b) no informar detalles específicos del método utilizado, c) no dar razones simplistas, $d$ ) no glorificar ni sensacionalizar el suicidio, e) no usar estereotipos y f) no aportar culpas (OMS, 2000).

La OMS y otros órganos internacionales crearon hace casi dos décadas informes para los profesionales de los medios de comunicación sobre cómo tratar informaciones relacionadas con el suicidio. Los informes parecen estar de acuerdo en cuáles son las prácticas periodísticas no deseadas: evitar el cubrimiento sensacionalista de suicidios, suprimir descripciones detalladas del método utilizado, no glorificar a las víctimas. Se recomienda que los medios ofrezcan información sobre posibles alternativas al suicidio, publicitar indicadores de riesgo y señales de advertencia.

Ciertos tipos de cubrimiento pueden ayudar a prevenir la imitación del comportamiento suicida. No obstante, existe siempre la posibilidad de que la publicidad sobre el suicidio 
pueda hacer que este parezca normal. Una cobertura repetitiva y continua del suicidio tiende a inducir y promover pensamientos suicidad, particularmente entre los adolescentes y adultos jóvenes (OMS, 2000, p. 7).

Por lo que se refiere específicamente al ámbito jurídico, en España concretamente, el artículo 39.4 de la Constitución Española proclama que los menores gozarán de la protección prevista en los acuerdos internacionales que velan por sus derechos. Por otra parte, el artículo 20.4 proclama la limitación de la libertad de expresión e información cuando colisiona con otros derechos fundamentales, tales como el derecho al honor, a la intimidad, a la propia imagen y a la protección de la juventud y de la infancia (VV. AA., 2016).

Desde un punto de vista general, la UNESCO ofrece directrices para la labor informativa sobre cuestiones que afectan a la dignidad y la intimidad. El código internacional de ética para la sociedad de la información de la UNESCO (2011), si bien no se detiene a contemplar aspectos sobre la infancia o el suicidio, sí reconoce la responsabilidad social periodística, así como el respeto por la privacidad y la dignidad de las personas, evitando calumnias e insinuaciones.

De igual modo, cabría hacer referencia aquí a la propuesta de otros códigos deontológicos en relación al tratamiento de los menores y el suicidio. A este respecto, la Federación Internacional de Periodistas, FIP (2018) en sus principios propone evitar el uso de estereotipos y la presentación de información sensacionalista que implique a menores. Igualmente recomienda analizar cuidadosamente las consecuencias de la publicación de material concerniente al menor minimizando así su posible daño. Por su parte, el código deontológico de la Federación de Asociaciones de Periodistas de España (FAPE) no recoge ninguna propuesta sobre el tratamiento del suicidio en los medios. No obstante, hace hincapié en información que afecten a menores:

4. e) Se prestará especial atención al tratamiento de asuntos que afecten a la infancia y a la juventud y se respetará el derecho a la intimidad de los menores (FAPE, 2017).

El diario El País, en su Manual de estilo, contempla el tratamiento del suicidio en sus informaciones pero no el del menor:

1.6. El periodista deberá ser especialmente prudente con las informaciones relativas al suicidio. En primer lugar, porque no siempre la apariencia coincide con la realidad, y también porque la psicología ha comprobado que estas noticias incitan a quitarse la vida a personas que ya eran propensas al suicidio y que sienten en ese momento un estímulo de imitación. Los suicidios deberán publicarse solamente cuando se trate de personas de relevancia o supongan un hecho social de interés general (Grijelmo et al., 2014).

Por su parte, el Libro de estilo del diario El Mundo se centra en respectar los principios de los menores en sus contenidos: 
IV. Protección de la infancia. Los medios de comunicación españoles han demostrado a veces una profunda insensibilidad ante los derechos de los niños. Por ejemplo, la identificación plena de delincuentes -o incluso supuestos delincuentes- juveniles ha sido frecuente en las páginas de los periódicos. Estos deben dotarse de normas internas estrictas para evitar la desprotección de niños y adolescentes en sus informaciones. Frecuentemente el laxismo de los medios en los tratamientos informativos, al no diferenciar automáticamente la forma de referirse a sujetos adultos e infantiles, contribuye a esa desprotección.

C.5. La identidad de los menores de edad y de los agentes de las fuerzas policiales debe ser -por razones diferentes- motivo de particular discreción en los medios informativos. Por ello se evitará que personas de esas características puedan ser identificadas en fotografías cuya publicación pondría en peligro, en el caso de los menores, sus derechos garantizados por la protección de la infancia (El Mundo, 1996).

La presencia de los menores en los medios de comunicación se ha vuelto más vulnerable en la Sociedad de la información. En cualquier caso, explica Manrique (2014, p. 4), por un lado, se han incrementado las dificultades para proteger a la infancia, pero también han crecido las posibilidades de intervención y difusión a su favor.

El incumplimiento del código deontológico se puede dar en mayor medida en los medios digitales por sus características de inmediatez, interactividad y multimedia, entre otras. De hecho, Suarez-Villegas (2015, p. 394) establece que la información que se ofrece a través de los cibermedios corre un mayor riesgo de caer en el sensacionalismo y no saber diferenciar entre lo banal y lo importante, en comparación con otros medios más tradicionales, particularmente de la prensa. La rapidez e instantaneidad hace que los diferentes medios de comunicación compitan por ser los primeros en publicar una información de alcance e interés. La rivalidad por la instantaneidad trae como consecuencia el menor control deontológico de la información. Otro aspecto a tener en cuenta de los medios es su contenido multimedia. La persecución de mayor target estimula el desarrollo de informaciones sensacionalistas que causen un efecto viral en los usuarios y las usuarias.

La búsqueda de la interactividad convierte las informaciones y/o recursos multimedia en sensacionalistas con el fin de obtener un mayor feedback. Por otra parte, se debe tener en cuenta que ciertas publicaciones negativas (como el acoso escolar y el suicidio, precisamente) pueden ser revisadas en la red en cualquier instante y lugar. Este aspecto podría tener efectos nocivos en el caso de acoso escolar, ya que la víctima puede ser objeto de mayores burlas o vejaciones y, en el caso del suicidio, puede alentar la tristeza de los familiares de la víctima. En suma, las publicaciones de medios digitales tienen mayor probabilidad de incumplimiento deontológico debido a sus características frente a las informaciones offline. Así lo indica Suarez-Villegas (2015) en las conclusiones de su análisis, donde recoge que los periodistas de medios tradicionales parecen más concienciados sobre la necesidad de cumplir con una serie de principios éticos y deontológicos, en comparación con los de los medios nativos digitales. 


\section{Objetivos y metodología}

No hay constancia de investigaciones previas que muestren las consecuencias del tratamiento mediático de menores víctimas de bullying que hayan derivado en suicidio. En vista de ello, este artículo examina programas, protocolos, códigos deontológicos e informes, junto con diferentes casos de cobertura mediática a los menores suicidados a causa de acoso escolar, con el objetivo de contribuir a arrojar luz sobre las posibles consecuencias de la publicación de este tipo de contenido informativo y sobre cómo mejorar su tratamiento evitando factores de riesgo.

Según la premisa general que guía esta investigación, las informaciones de los medios de comunicación sobre menores, bullying y suicidio evidencian una mayor problemática o riesgo deontológico por diversos motivos.

La variable menor de edad debe vincularse al ámbito jurídico y al hecho de que los y las protagonistas de la información sean menores de edad, además de todo el marco deontológico que respalda dicha jurisprudencia. Asimismo, el acoso escolar (o bullying) no se encuentra regulado por ningún documento, aunque sí es un acto de relevancia social, llegando a ser un tema tabú hace dos décadas. Existen manuales de intervención sobre el acoso escolar, pero no una normativa que la restringa. En esta investigación trataremos de reflexionar si es adecuada o no su publicación.

Por su parte, tomamos el suicidio como factor de riesgo basándonos en la "teoría del aprendizaje por imitación" de Bandura (1987). La teoría del aprendizaje social sugiere una explicación acerca del posible reforzamiento conductual de los medios de comunicación sobre el contagio de la conducta suicida. Por ello, se parte de la hipótesis que el informar sobre suicidios incrementa el riesgo de imitación. Asimismo, el "efecto Werther", denominado por el sociólogo David Phillips (1974), señala que información acerca del suicidio provoca la elevación de su tasa en la sociedad. Según se ha indicado, hace casi dos décadas la OMS (2000) elaboró un documento con pautas a seguir en las informaciones relacionadas con tal suceso.

Diversas investigaciones sobre el efecto de imitación de las informaciones sobre el suicidio publicadas por los medios de comunicación (Stack, 1996, 2005; Pirkis et al., 2006) muestran un agravamiento de dicho efecto durante los tres primeros días tras la publicación de la noticia, disminuyendo este en aproximadamente dos semanas. En cuanto al contenido, según estos mismos estudios, la causalidad se incrementa cuando se detalla el método y se glorifica la conducta y sus consecuencias. Según indican Sisask \& Värnik (2012), con relación al efecto modelador de la cobertura de los medios sobre el suicidio, la imitación también puede reforzarse particularmente en el caso de celebridades y adolescentes.

A estas tres variables, se suma el hecho de que los medios digitales, por sus propias características, según se ha señalado, evidencian mayores factores de riesgo deontológico en el tratamiento del suicidio de menores por casos de bullying. En otras palabras, los medios digitales son rápidos, interactivos y tienen un alcance internacional. Sin embargo, estas 
características (a priori positivas) pueden provocar el incumplimiento de la deontología y favorecer el sensacionalismo.

En vista de lo indicado, esta investigación tiene como objetivo principal conocer el nivel de cumplimiento de la norma ética y deontológica en informaciones de menores suicidados por causa del acoso escolar. Derivado de este objeto general, el análisis discute sobre la necesidad de publicar noticias sobre suicidio de menores, o sobre la contribución de estas a concienciar a la sociedad y ayudar a posibles futuras víctimas. Estas cuestiones se abordarán a lo largo de la investigación donde se revisará la diferente literatura existente ya citada previamente (Phillips, 1974; Olweus, 1998; Stack, 2005; Pirkis et al., 2006; Cerezo, 2009; McCombs \& Shaw, 1972; Chomsky \& Herman, 2013; Bandura, 2001) haciendo hincapié en los datos aportados desde el ámbito psicológico, sociológico, comunicativo y educacional.

Como se ha sostenido, los medios publican noticias en relación al acoso escolar, pero cuando se trata de suicidio de jóvenes y adolescentes suelen acogerse al "silencio informativo", con excepciones. En este sentido, la investigación se apoya en un estudio de casos que han sido seleccionados en función de su interés social y su particular cobertura mediática.

Concretamente, en esta investigación se analizan tres casos de suicidio derivado de acoso escolar por su relevancia social y repercusión judicial. El primer caso es el del joven Jokin Ceberio, quien se suicidó el 21 de septiembre de 2004 en la Muralla de Hondarribia (Donostia, País Vasco) con 13 años de edad. El tratamiento de los medios de comunicación españoles sobre el suicidio del menor fue un caso pionero. Nueve años más tarde, aparece el caso de Carla Díaz Magnien, quien se suicida el 11 de abril de 2013 en el acantilado de la Providencia (Gijón, Asturias) con 14 años de edad. Le sigue dos años después Diego González, quien se quita la vida el 14 de octubre de 2015 en su hogar en Leganés (Madrid), con 11 años de edad.

Las informaciones sobre los tres casos se abordarán desde dos medios nacionales en su versión online: ElPaís.com y El Mundo.es. Según los informes trimestrales del Estudio General de Medios, EGM (2017) y el informe anual de la Oficina de Justificación de la Difusión, OJD (2017), El País y El Mundo son los medios nacionales de prensa diaria tradicional de mayor difusión en papel y en la red de España. Además, ambos medios son representativos de distintas corrientes ideológicas: El País es un medio más afín a una ideología de izquierdas, mientras que El Mundo se sitúa en el extremo contrario, por lo que parece interesante conocer el tratamiento de ambos para obtener una perspectiva más amplia del caso.

Para esta investigación se ha optado por el análisis de informaciones recogidas por medios digitales debido a su mayor accesibilidad, su mayor impacto y sobre todo, por las características (inmediatez, interactividad, multimedia) que estos medios poseen que pueden limitar el cumplimiento de la deontología periodística. Como se ha señalado, resulta particularmente interesante analizar hasta qué punto estas características favorecen o amparan el incumplimiento de la deontología en informaciones que contengan suicidio y menores. 
Para la selección de las unidades de análisis se consideraron todas aquellas informaciones publicadas por las versiones electrónicas ElPaís.com y ElMundo.es que contenían los nombres de las víctimas en alguno de los elementos de titulación o cuerpo informativo. La recuperación de dichas informaciones se llevó a cabo de la hemeroteca o archivo digital del cibermedio.

Para realizar la búsqueda hemerográfica en cada uno de los medios se utilizaron diversas palabras clave: "menor", "suicidio", "acoso escolar", "bullying" y el nombre de las víctimas (Jokin Ceberio, Carla Díaz Magnien y Diego González). Por lo que se refiere a la delimitación temporal del estudio, se consideraron todas las noticias publicadas desde la fecha más cercana al suicidio hasta la actualidad, con la idea de hacer un seguimiento evolutivo del tratamiento deontológico de cada caso. En total, se analizaron 41 informaciones, 21 de ellas publicadas por Elpaís.com, entre las cuales catorce se refieren al caso de Jokin Ceberio, 3 al caso de Carla Díaz y las cuatro restantes al de Diego González. De las 20 informaciones publicadas por Elmundo.es, 9 tratan el primer caso, 3 el segundo caso y 8 se relacionan con el último caso.

El análisis del tratamiento deontológico de estas informaciones sobre suicidios derivadas del bullying se llevó a cabo un análisis cualitativo y descriptivo del contenido. De manera particular, el análisis ha buscado aquellos elementos discursivos y de contenido de mayor sensacionalismo, así como el tipo de recursos multimedia que se emplean y todo lo relativo a los comentarios online, por considerarse esta un recurso que promueve el debate de la opinión pública, siendo distintivo de los medios online.

\section{Resultados}

El caso de Jokin Ceberio data en 2004 cuando la publicación del suicidio del menor despierta una alarma social que marca un antes y un después en la información sobre el acoso escolar en España. (Navarrete-Galiano, 2009). En este caso, se debe tener en cuenta que el tío de Jokin Ceberio (Miguel Ángel Ceberio) fue director del diario El País desde 1993 hasta 2006, para pasar posteriormente a ser el director general del medio desde 2006 hasta 2011. Podría ser esta una de las razones por las que en comparación con El Mundo, El País se acogió en mayor medida al silencio informativo, al utilizar una menor cantidad de recursos visuales en fechas cercanas al suicidio, mientras que en años posteriores al suicidio todas las noticias de ambos medios sobre el caso están acompañadas de apoyo visual.

Llama la atención que en los años cercanos al suicidio de Jokin, los medios respetaron la intimidad del menor. Sin embargo, años después, algunos medios de comunicación locales publicaron el rostro del menor. Las imágenes que acompañan a la información del suicidio de Jokin se repiten en ambos medios donde se puede ver el lugar donde el joven perdió la vida: la Muralla de Fuenterrabía. Al publicar la fotografía del lugar donde ocurrió el suicidio, se incumple las normas que propone el programa SUPRE. Concretamente, ElMundo.es contiene un 55\% noticias con apoyo visual sobre el caso de Jokin Ceberio, mientras que ElPaís.com contiene un $21 \%$. Este dato resulta significativo y puede deberse 
a tres factores: a) la buena praxis de los profesionales de la información en relación al programa SUPRE, b) la influencia del director del medio e, incluso, al menor interés por aquel entonces hacia la multimedialidad y c) el valor del fotoperiodismo online en un momento en el que el propio ciberperiodismo comenzaba a adquirir una entidad propia y diferenciada.

Con relación a los titulares, ElMundo.es pone su foco en las denuncias de la familia hacía los agresores y el centro escolar: "La familia del joven que se suicidó tras sufrir acosos denuncia la responsabilidad del instituto" (30/IX/2004). "La Fiscalía imputa malos tratos a los compañeros del joven que se suicidó en Hondarribia y pide abrir un juicio" (7/ IV/2005). "Una testigo protegida afirma que un imputado le reconoció que hubo golpes y burlas contra Jokin" (27/IV/2005). "La familia de Jokin recurrirá las penas impuestas a los acosadores por considerarlas ridículas" (13/V/2005). "La juez suspende la pena de siete de los condenados por el caso de Jokin" (23/IX/2005). "Libertad vigilada para los siete jóvenes condenados tras el suicidio de Jokin" (28/VIII/2006). "El tío de Jokin cree que los padres de alumnos deberían echarse a temblar" (11/II/2011).

Los titulares que ofrece ElPaís.com guardan relación con los citados previamente: "Los supuestos acosadores de Jokin dicen que todo el instituto participaba en las vejaciones" (5/X/2004). "La familia de Jokin denuncia a los responsables del instituto por 'dejadez' ante el acoso" (11/III/2005). "Los acusado de acosar a Jokin admiten 'burlas y cachetes' pero niegan haberle pegado palizas" (25/IV/2005). "La madre de Jokin dice que su hijo le confesó que sus agresores eran los ocho alumnos imputados" (27/IV/2005). "Los padres de Jokin confían en que su muerte sirva para evitar nuevos casos de acoso escolar" (21/ IX/2005). "La familia de Jokin discrepa del fallo que exime de culpa a su instituto" (11/ II/2011).

Salvo excepciones, ambos medios evitan incluir la palabra "suicidio" en los titulares. No obstante, destaca la diferente redacción del pie de foto que acompaña la fotografía de la Muralla de Fuenterrabía. Mientras ElPaís.com manifiesta "lugar de la muralla de Hondarribia donde cayó Jokin", ElMundo.es declara "lugar donde se suicidó Jokin", ambos publicados en la misma fecha (13/V/2005). En el cuerpo de la noticia se especifica el tipo de acoso escolar sufrido por el adolescente, llegando incluso a rozar el sensacionalismo: se aporta información sobre las vejaciones, el maltrato físico y psicológico, acompañando esta información de diferentes fuentes orales que detallan los actos relatados. Por otra parte, la posibilidad de comentar las noticias aparece desactivada en las informaciones relacionadas con Jokin Ceberio.

Aunque las fotografías sobre el rostro del menor se protegen en ambos medios digitales, no se percibe la misma actuación en relación a su nombre, que aparece de manera completa, incluso en los titulares, en lugar de mediante siglas, lo que permitiría amparar así su derecho de intimidad y el de sus familiares. Igualmente, el método de suicidio ejecutado por el menor se refleja detalladamente en la noticia, acompañado de la fotografía del lugar donde el menor se suicidó. 
El caso de Carla Díaz Magnien contrasta con el de Jokin Ceberio, debido al total incumplimiento deontológico por parte de ambos medios de comunicación tanto en los manuales de referencia como en las citadas recomendaciones que otorga el programa SUPRE. Hay que tener en cuenta que en comparación con el anterior caso, el suicidio de Carla sucede nueve años más tarde, en un entorno y momento donde gobiernan la interactividad y multimedialidad en la web. Aunque el caso de la menor es menor en la cantidad de información publicada por ambos medios, sus noticias recogen titulares más sugerentes, con apoyo visual que incumple la ética periodística y con la habilitación de comentarios.

Los titulares de ElMundo.es mencionan tanto el suicidio, como el acoso escolar, y se centran en la denuncia de la madre de la víctima: "Agresión escolar y salto al vacío" (23/III/2014). "La Fiscalía imputa a dos niñas por el suicidio de Carla" (25/IX/2014). "“Gente como tú acabó con ella"” (4/XI/2014). "Condenan a dos menores por acosar a una adolescente que se suicidó en Gijón" (31/XII/2014), "Es ridículo. Un menor mata a otro y no se le puede tocar" (2/I/2015). Por su parte, ElPaís.com mantiene la misma línea: "Me decían: son cosas de crías" (28/IX/2014), "Condenan a dos menores por acosar a otra que se suicidó" (30/XII/2014).

El cuerpo de la noticia recoge las vejaciones que sufrió la menor en el centro escolar con relación a su aspecto físico y orientación sexual. Las burlas e injurias se detallan a través de diversas fuentes directas del instituto. En este caso existen escasas diferencias en el incumplimiento del código deontológico por parte de El País y El Mundo. En ambos medios se publican fotografías de la menor y se busca el sensacionalismo a través de imágenes retocadas dramáticamente sobre la madre de la víctima. Por otro lado, ElPaís. com y ElMundo.es publican sus informaciones sobre el suicidio de la menor con apoyo visual. Frente al primer caso examinado, aquí resalta el sensacionalismo y la publicación de la imagen de la menor.

En este caso, el retoque fotográfico en la noticia es un recurso recurrente que busca crear un mayor dramatismo y, por tanto, sensacionalismo. En comparación con el tratamiento visual del primer caso (el cual pasaba desapercibido con imágenes de planos generales) este segundo caso pone el foco en planos medios protagonizados por la madre de la menor y el efecto Droste ${ }^{2}$. Se crea un juego de sombras, tapando el rostro de la madre con una mirada, en ocasiones pérdida y otras veces directa al receptor. También se observan las manos de la madre sosteniendo una foto de su hija. Mediante esta técnica se busca llamar la atención de los lectores.

Del mismo modo, El Mundo publica una serie de informaciones acompañadas de vídeos donde aparece la madre de la menor denunciando el acoso escolar que provocó el suicidio de su hija. Junto con los recursos multimedia, ElMundo.es habilita la posibilidad de comentar todas las noticias de la menor, posibilidad vigente en el momento del análisis. En

2 El efecto Droste consiste en una imagen que incluye dentro de ella una versión de menor tamaño de sí misma. 
ese sentido, en julio de 2018, teniendo en cuenta todas las noticias analizadas sobre el caso, este reunía un total de 159 comentarios (consultado el 21/VII/2018). A partir de este caso es posible advertir una diferencia en el tratamiento deontológico y mediático por parte de los dos medios analizados.

El suicidio de Diego González ocurrió en octubre de 2016 en Leganés (Madrid). Lo más llamativo del caso, a nivel informativo, fue la publicación de la carta manuscrita de despedida del menor. La divulgación de la carta y su interpretación por parte de los medios se aleja de toda propuesta deontológica. A ello se añaden otras acciones, como la publicación del rostro del menor y de su habitación, con titulares e informaciones relativos a las vejaciones a las que supuestamente había sido sometido.

En cuanto a los titulares de ElMundo.es se puede comprobar un contraste con los dos casos anteriores: "Diego, de 11 años, antes de suicidarse: 'No aguanto ir al colegio"" (20/I/2016). "Ni sus padres ni en el colegio detectamos que se acosara a Diego" (21/I/2016). "Las reacciones de los lectores: 'Diego, no eres débil. Eres alguien que no contó con la ayuda suficiente"” (21/I/2016). "Abusos sexuales en el colegio según el testigo que reabre el 'Caso Diego"” (30/I/2016). "Una niña de clase de Diego, también acosada: 'Le llamaban maricón"” (3/II/2016). "La familia de Diego exige una rectificación pública al doctor Cabrera por sus 'hirientes' declaraciones" (5/II/2016). "El 'mea culpa' de José Cabrera ante los padres de Diego, el niño que se suicidó" (7/II/2016). "La Justicia archiva el caso de Diego, el niño que se suicidó con 11 años: No aguanto ir al colegio" (26/V/2018).

En contraposición, ElPaís.com sigue manteniendo sus titulares alejados del sensacionalismo: "Madrid revisa el suicidio de un menor por un posible acoso escolar" (21/I/2016). "La juez archiva por segunda vez el caso del niño que se suicidó en Madrid" (29/II/2016). "Los padres del niño que se suicidó en Leganés piden anular el archivo del caso" (16/III/2016).

La lectura de los titulares de los dos medios nacionales con relación a este caso permite advertir un mayor sensacionalismo en los titulares de El Mundo. En dicho medio, la utilización de vejaciones y de discursos orales empapados de emocionalidad subraya la búsqueda de dramatismo y sensacionalismo. Además, El Mundo fue el primero en publicar la carta manuscrita de despedida que Diego dejó a su familia. En la carta explica las razones por las cuales comete el suicidio y el deseo de que su familia sea feliz. Los comentarios aparecen habilitados y obtienen gran retroalimentación por parte de los usuarios, a partir de un total de 642 comentarios (consultado el 21/VII/2018). Esta cifra supera significativamente la de los comentarios recogidos en la cobertura mediática de Carla Díaz. En este caso, la publicación de la carta manuscrita de la menor obtuvo 197 comentarios.

Ninguno de los dos medios seleccionados publica el lugar del suicidio o su domicilio, si bien este dato sí es revelado en el cuerpo de la noticia, al igual que el tipo de suicidio. ElPaís.com presenta un $75 \%$ de sus informaciones con acompañamiento multimedia, mientras ElMundo. es difunde todas sus noticias con apoyo audiovisual. La imagen más recurrente es el primer plano de los padres del menor con una mirada directa al espectador. Los vídeos presentan la declaración de los padres sobre lo sucedido y varias imágenes del menor. 
A través del análisis de los tres casos se puede comprobar la existencia de una evolución significativa y un tratamiento diferente desde el primer caso a la actualidad. Parece que a medida que se dan más casos de bullying y suicidio, las fotografías pasan de ser más "frías" y distantes del lector, con planos generales y sin recursos figurativos, para estar llenas de dramatismo con retoques fotográficos, además de recurrir a primeros y medios planos útiles para captar la atención del usuario. A esto se suma, por parte de El Mundo, la habilitación de los comentarios en los dos últimos casos y unos titulares que tienden hacia el sensacionalismo.

En definitiva, los medios no se han acogido en ninguno de los casos al silencio informativo del suicidio, ni a la protección a la infancia, al citar los nombres completos de las víctimas, el tipo de suicidio y también al publicar el rostro de los menores, salvo en el caso de Jokin Ceberio. El incumplimiento de la deontología es más notorio en El Mundo que en El País, ya que el primero incumple con lo indicado por el programa SUPRE de la OMS: la publicación del método, el rostro y el nombre de los menores, la publicación de alternativas o recursos de ayuda, la habilitación de comentarios en noticias sobre el suicidio y la búsqueda de sensacionalismo. Mediante el análisis realizado desde el primer caso fechado en el año, hasta el último (fechado en 2016) se confirma que la evolución en el tratamiento del acoso escolar derivado en suicidio se caracteriza por un incumplimiento reiterado de la deontología periodística.

\section{Conclusiones}

La mayoría de las noticias analizadas sobre suicidio de menores en ElMundo.es y ElPaís. com no cumplen con las recomendaciones del programa SUPRE (Suicide Prevention) creado por la OMS (2000). El programa indica cómo informar sobre el suicidio y qué aspectos deben ser evitados. El programa menciona que el cubrimiento sensacionalista de suicidios deberá evitarse de manera diligente. Concretamente cita la importancia de evitar fotografías de la víctima, del método empleado y de la escena del suicidio. Aun así, ambos medios nacionales publican fotografías de las víctimas, exceptuando el caso de Jokin Ceberio. De igual modo, se nombra el método de suicidio utilizado, en los tres casos: arrojarse al vacío.

El SUPRE indica que ciertos escenarios (acantilados, puentes, edificios altos, entre otros) al estar asociados con el suicidio aumenta el riesgo de imitación. En consecuencia, es posible concluir que la cobertura de las noticias del suicidio de menores por parte de ambos medios españoles es sensacionalista en los dos de los tres casos examinados. El Mundo sobresale en dicho incumplimiento incluso en contra de lo establecido por su propio código deontológico respecto al tratamiento del suicidio y menores. De hecho, El Mundo recoge meticulosamente el tratamiento del menor y del suicido en su Libro de estilo (1996), en contraste con ElPaís.com que solamente contempla el suicidio.

En cuanto a las propuestas positivas de la OMS (2000) para los profesionales de los medios de comunicación sobre cómo informar sobre suicidios, los medios españoles seleccionados no 
cumplen con tales recomendaciones. En los casos analizados en ElPaís.com y ElMundo.es no proporcionan información sobre líneas de ayuda. Asimismo, tampoco se resaltan alternativas al suicidio y menos aún se informa sobre indicadores de riesgo o señales de advertencia.

En cuanto a la protección de la infancia, no se oculta el rostro de los y las menores ni se oculta el nombre bajo siglas lo cual implica una vulneración al derecho a la intimidad y protección de la imagen del menor. Sorprende que los medios de comunicación contemplen estas normas en sus propios libros de estilo para posteriormente incumplirlas, teniendo además a la FAPE (Federación de Asociaciones de Periodistas de España) como referente que aboga por el derecho a la intimidad del menor.

La desactivación de comentarios al informar sobre el suicidio parece una medida preventiva que proponen algunos medios digitales, como por ejemplo el manual de estilo de la Radiotelevisión Pública Vasca, EITB (Martín Sabarís et al., 2016). Esto no se cumple en los casos de Carla Díaz Magnien y Diego González, donde la posibilidad de comentarios aparece habilitada con una gran tasa de respuestas por parte de los lectores y las lectoras en la web de ElMundo.es. No existen evidencias de los motivos que empujan en algunos casos a deshabilitar la posibilidad de feedback y, en otros, a activarlos.

Respecto a la evolución temporal del tratamiento del bullying y el suicidio en los medios de comunicación españoles, se da un salto cualitativo desde el primer caso analizado al último. Por un lado, la cobertura mediática del Jokin Ceberio (2004) no posee una gran carga visual sensacionalista frente a los casos posteriores, Carla Díaz Magnien (2013) y Diego González (2015), que contienen en todas sus informaciones recursos multimedia, sobre el rostro de ambos menores, así como imágenes y declaraciones llenas de dramatismo.

El análisis específico del tratamiento mediático (titulares, texto, recursos multimedia, cumplimiento deontológico, activación de comentarios) permite concluir que no existen diferencias significativas entre los dos medios en el tratamiento de los tres casos considerados. En este sentido, apuntamos como una posible línea de estudio de interés el análisis de los casos considerado en otros medios con un carácter más local, así como el estudio de casos similares en otros contextos geográficos.

Por otro lado, observando las tasas de suicidio en los meses posteriores al suicidio de los tres menores, no hay datos significativos que indiquen que se genere un "efecto Werther" de imitación del suicidio. Este resultado puede desmitificar el impacto de la conducta imitativa, si bien no obviamos que el efecto puede agravarse cuando el suicidio lo comete un personaje célebre, como han señalado Müller (2011) y Herrera et al. (2015).

Según recomiendan Pirkis et al. (2006), resulta fundamental la colaboración entre profesionales de la información y los profesionales de salud mental con la idea de evitar el riesgo de daño y promover oportunidades para la educación. Pirkis et al. (2006) sugieren difundir informaciones confidenciales sobre el suicidio, sin glorificarlo o idealizarlo, sin detalles visuales del método, pero sí enfatizando en las consecuencias, sus riesgos y las fuentes de ayuda para personas vulnerables. 
Probablemente sea adecuado describir y contar cuáles han sido las conductas violentas hacía el menor, para demostrar que el bullying tiene múltiples formas, creando así diferentes perfiles de acosadores para que la sociedad tenga un mejor foco de visión e intervenga. Diferentes investigaciones defienden el tratamiento del suicidio en los medios de comunicación (Garrido-Fabián et al., 2018; Herrera et al., 2015) mediante la hipótesis de la existencia del llamado "efecto Papageno" cuando se da un abordaje periodístico responsable que siguiendo las pautas establecidas podría tener un efecto de reducción de la conducta suicida. Se deben dejar los detalles de las vejaciones y solo centrarse en los hechos concretos, sin entrar en especificaciones, en otras palabras, huir del sensacionalismo.

\section{Referencias}

Alsedo, Q., Herraiz, P. \& Durán, L. (20 de enero de 2016). Diego, de 11 años, antes de suicidarse: "No aguanto ir al colegio". El Mundo. Recuperado de http://www. elmundo.es/madrid/2016/01/20/569ea93246163fd12b8b4626.html

Alsedo, Q. \& Herraiz, P. (3 de febrero de 2016). Una niña de la clase de Diego, también acosada: "Le llamaban maricón". El Mundo. Recuperado de http://www.elmundo. es/sociedad/2016/02/03/56b10600268e3e484b8b4571.html

Álvarez, P. (21 de enero de 2016). Madrid revisa el suicidio de un menor por un posible acoso escolar. El País. Recuperado de https:/elpais.com/politica/2016/01/20/ actualidad/1453319134_091881.html

Álvarez, P. (29 de febrero de 2016). La juez archiva por segunda vez el caso del niño que se suicidó en Madrid. El País. Recuperado de https://elpais.com/politica/2016/02/29/ actualidad/1456761947_668589.html

Bandura, A. (1987). Teoría del aprendizaje social. Madrid: Espasa.

Bandura, A. (2001). Social Cognitive Theory of Mass Communication. Media Psychology, 3, 265-299. Recuperado de http://cogweb.ucla.edu/crp/Media/Bandura_01.pdf

Cabrera, J. (7 de febrero de 2016). El "mea culpa" de José Cabrera ante los padres de Diego, el niño que se suicidó. El Mundo. Recuperado de http://www.elmundo.es/ sociedad/2016/02/07/56b61caf22601dbc038b468c.html

Cerezo Ramírez, F. (2002). La violencia en las aulas. Madrid: Pirámide.

Cerezo Ramírez, F. (2009). Bullying: análisis de la situación en las aulas españolas. International Journal of Psychology and Psychological Therapy, 9, 367-378.

Chomsky, N.\& Herman, E.(2013). Los guardianes de la libertad. Propaganda, desinformación y consenso en los medios de comunicación de masas. Barcelona: Planeta. 
Cohen, B. (1963). The Press and Foreign Policy. Nueva Jersey: Princeton University Press.

El Mundo (1996). Libro de estilo de El Mundo. Madrid: Temas de hoy.

El Mundo (30 de septiembre de 2004). La familia del joven que se suicidó tras sufrir acosos denuncia la responsabilidad del instituto. Recuperado de http://www. elmundo.es/elmundo/2004/09/30/sociedad/1096556527.html

El Mundo (7 de abril de 2005). La Fiscalía imputa malos tratos a los compañeros del joven que se suicidó en Hondarribia y pide abrir un juicio. Recuperado de http:// www.elmundo.es/elmundo/2005/04/07/sociedad/1112893220.html

El Mundo (27 de abril de 2005). Una testigo protegida afirma que un imputado le reconoció que hubo golpes y burlas contra Jokin. Recuperado de http:/www.elmundo.es/ elmundo/2005/04/27/sociedad/1114593908.html

El Mundo (14 de mayo de 2005). La familia de Jokin recurrirá las penas impuestas a los acosadores por considerarlas ridículas. Recuperado de http:/www.elmundo.es/ elmundo/2005/05/13/sociedad/1116006637.html

El Mundo (23 de septiembre de 2005). La juez suspende la pena de siete de los condenados por el caso de Jokin. Recuperado de http://www.elmundo.es/elmundo/2005/09/23/ sociedad/1127474482.html

El Mundo (28 de agosto de 2006). Libertad vigilada para los siete jóvenes condenados tras el suicidio de Jokin. Recuperado de http://www.elmundo.es/elmundo/2006/08/28/ espana/1156779800.html

El Mundo (11 de febrero de 2011). El tío de Jokin cree que los padres de alumnos deberían echarse a temblar. Recuperado de http://www.elmundo.es/elmundo/2011/02/11/ paisvasco/1297435731.html

El Mundo (21 de enero de 2016). Las reacciones de los lectores: "Diego, no eres débil. Eres alguien que no contó con la ayuda suficiente". Recuperado de http://www. elmundo.es/sociedad/2016/01/21/56a0b97a46163ff0018b4603.html

El Mundo (5 de febrero de 2016). La familia de Diego exige una rectificación pública al doctor Cabrera por sus "hirientes" declaraciones. Recuperado de http://www. elmundo.es/sociedad/2016/02/05/56b4ca9f268e3e4c158b45d0.html

El País (5 de octubre de 2004). Los supuestos acosadores de Jokin dicen que todo el instituto participaba en las vejaciones. Recuperado de https://elpais.com/ sociedad/2004/10/05/actualidad/1096927202_850215.html 
El País (11 de marzo de 2005). La familia de Jokin denuncia a los responsables del instituto por "dejadez" ante el acoso. Recuperado de https:/elpais.com/ sociedad/2005/03/11/actualidad/1110495601_850215.html

El País (25 de abril de 2005). Los acusados de acosar a Jokin admiten "burlas y cachetes" pero niegan haberle pegado palizas. Recuperado de https:/elpais.com/ sociedad/2005/04/25/actualidad/1114380003_850215.html

El País (27 de abril de 2005). La madre de Jokin dice que su hijo le confesó que sus agresores eran los ocho alumnos imputados. Recuperado de https:/elpais.com/ sociedad/2005/04/27/actualidad/1114552802_850215.html

El País (21 de septiembre de 2005). Los padres de Jokin confían en que su muerte sirva para evitar nuevos casos de acoso escolar. Recuperado de https:/elpais.com/ sociedad/2005/09/21/actualidad/1127253603_850215.html

El País (11 de febrero de 2011). La familia de Jokin discrepa del fallo que exime de culpa a su instituto. Recuperado de https://elpais.com/sociedad/2011/02/11/ actualidad/1297378822_850215.html

El País (16 de marzo de 2016). Los padres del niño que se suicidó en Leganés piden anular el archivo del caso. Recuperado de https://elpais.com/ccaa/2016/03/16/ madrid/1458125119_476734.html

Estudio General de Medios, EGM (2017). Informes trimestrales de 2017. Recuperado de https://www.aimc.es/blog/entrega-resultados-egm-3a-ola-2017/

Federación de Asociaciones de Periodistas de España, FAPE (2017). Código deontológico. Recuperado de http://fape.es/home/codigo-deontologico/

Federación Internacional de Periodistas, FIP (2018). Declaración de principios de la FIP sobre la conducta de los periodistas. Recuperado de http://www.ifj.org/es/ la-fip/declaracion-de-principios-de-la-fip/

Garrido-Fabián, F., Eleazar Serrano-López, A. \& Catalán-Matamoros, D. (2018). El uso de los periodistas de las recomendaciones de la OMS para la prevención del suicidio. El caso del periódico ABC. Revista Latina de Comunicación Social, 73, pp. 810-827. Recuperado de http://www.revistalatinacs.org/073paper/1283/RLCS-paper1283.pdf

Gaviria, E., López, M. \& Cuadrado, I. (2013). Introducción a la psicología social. Madrid: Editorial Sanz y Torres.

Gosálvez, P. (28 de septiembre de 2014). "Me decían: "Son cosas de crías"”. El País. Recuperado de https://elpais.com/sociedad/2014/09/27/ actualidad/1411839254_086464.html 
Gosálvez, P. (30 de diciembre de 2014). Condenadas dos menores por acosar a otra que se suicidó. El País. Recuperado de https:/elpais.com/politica/2014/12/30/ actualidad/1419943490_088281.html

Grijelmo, A. et al. (2014). Libro de estilo de El País. Madrid: Aguilar.

Herraiz, P. \& Alsedo, Q. (30 de enero de 2016). Abusos sexuales en el colegio según el testigo que reabre el "Caso Diego". El Mundo. Recuperado de http://www. elmundo.es/sociedad/2016/01/29/56ab64e746163f61428b464f.html

Herrera Ramírez, R., Ures Villar, M. \& Martínez Jambrina, J. (2015). El tratamiento del suicidio en la prensa española: ¿efecto Werther o efecto papageno? Revista de la Asociación Española de Neuropsiquiatría, 35 (125), 123-134. Recuperado de http://scielo.isciii.es/pdf/neuropsiq/v35n125/original08.pdf

Instituto Nacional de Estadística, INE (2017). Defunción según la causa de muerte. Año 2016. Recuperado de http://www.ine.es/prensa/edcm_2016.pdf

Magnien, M. (4 de noviembre de 2014). “Gente como tú acabó con ella". El Mundo. Recuperado de http://www.elmundo.es/espana/2014/11/04/54583a8422601dd73 18b4580.html

Manrique, E. (2014). Código ético periodístico para la infancia vulnerable. Madrid: Aldeas Infantiles SOS de España.

Martín Sabarís, R. et al. (2016). Libro de estilo de EiTB. Bilbao: Euskal Irrati Telebista.

Martínez Verdú, R. (2007). Bullying y medios de comunicación. En L. Álvarez, J. Evans \& O. Crespo (Eds.), Comunicación e Xuxentude: Actas do Foro Internacional (pp. 171-182). Santiago de Compostela: Colexio Profesional de Xornalistas de Galicia.

Mason, K. (2008). Cyberbullying: a preliminary assessment for school personnel. Psychology in the School, 45(4), 323-348.

McCombs, M. \& Shaw, D. (1972). The agenda-setting function of the mass media. Public Opinion Quarterly, 36, 176-185.

Müller, F. (2011). El "Efecto Werther": gestión de la información del suicidio por la prensa española en el caso de Antonio Flores y su repercusión en los receptores. Cuadernos de Gestión de Información, 1, 65-71. Recuperado de http://revistas. um.es/gesinfo/article/view/207541/166191

Navarrete-Galiano Rodríguez, R. (2009). Los medios de comunicación y la conciencia social en España frente al acoso escolar. Estudios sobre el mensaje periodístico, $15,335-345$. 
Noelle-Neuman, E. (1977). Turbulences in the climate of opinion: Methodological applications of the Spiral of Silence Theory. Public Opinion Quarterly, 41(2), 134-158.

Oficina de Justificación de la Difusión, OJD (2017). Informe anual. Recuperado de www.ojd.es

Olmo López, A. \& García Fernández, D. (2014). “El tratamiento de las noticias sobre suicidios. Una aproximación a su reflejo en los medios de comunicación". Estudios sobre el Mensaje Periodístico, 20(2), 1149-1163.

Olweus, D. (1998). Conductas de acoso y amenaza entre escolares. Madrid: Morata.

Organización de las Naciones Unidas para la Educación, la Ciencia y la Cultura, UNESCO (2011). Código de ética para la sociedad de la información, propuesto por el Consejo Intergubernamental del programa Información para todos (PIPT). Recuperado de http://unesdoc.unesco.org/images/0021/002126/212696s.pdf

Organización Mundial de la Salud, OMS (2000). Prevención del suicidio: Un instrumento para profesionales de los medios de comunicación. Trastornos mentales y cerebrales. Departamento de salud mental y toxicomanías. Ginebra: OMS.

Orte Socías, C. (2006). "Nuevas perspectivas sobre la violencia y el bullying escolar". Revista Panorama Social, 3, pp. 27-41.

Ortiz, A. (21 de enero de 2016). Ni sus padres ni en el colegio detectamos que se acosara a Diego. El Mundo. Recuperado de http://www.elmundo.es/sociedad/2016/01/21/ 56a141cde2704e47398b45e4.html

Pérez Camarero, S. (2009). El suicidio adolescente y juvenil en España. Revista de Estudios de Juventud, 84, 126-143.

Phillips, D. (1974). The influence of suggestion on suicide: substantive and theorical implications of the Werther effect. American Sociological Review, 39, 340-354.

Pirkis, J., Burgess, P., Francis, C., Warwick, R. \& Jolley, D. (2006). “The relationship between media reporting of suicide and actual suicide in Australia". Social Science \& Medicine, 62(11), 2874-2886.

Simón, P. (23 de marzo de 2014). Agresión escolar y salto al vacío. El Mundo. Recuperado de http://www.elmundo.es/espana/2014/03/23/532e0acde2704e4f3d8b4574.html

Simón, P. (26 de mayo de 2018). La Justicia archiva el caso de Diego, el niño que se suicidó con 11 años: "No aguanto ir al colegio". El Mundo. Recuperado de http:// www.elmundo.es/papel/historias/2018/05/26/5b08278046163faf258b4661.html 
Simón, P. \& Del Gallo, P. (25 de septiembre de 2014). La Fiscalía imputa a dos niñas por el suicidio de Carla. El Mundo. Recuperado de http://www.elmundo.es/espana/20 14/09/24/5422ac82e2704ec76d8b4585.html

Simón, P. \& Yanke, R. (31 de diciembre de 2014). Condenan a dos menores por acosar a una adolescente que se suicidó en Gijón. El Mundo. Recuperado de http://www. elmundo.es/espana/2014/12/30/54a2953eca474127548b4576.html

Sisask, M. \& Värnik, A. (2012). Media roles in suicide prevention: a systematic review. International Journal of Environmental Research and Public Health, 9(1), 123 138.

Stack, S. (1996). The effect of the media on suicide: evidence from Japan, 1955-1985. Suicide and Life-Threatening Behavoir, 26(2), 132-142.

Stack, S. (2005). Suicide in the media: A quantitative review of studies based on nonfictional stories. Suicide and Life Threatening Behavior, 35(2), 121-133.

Suárez-Villegas, J. (2015). Nuevas tecnologías y deontología periodística: comparación entre medios tradicionales y nativos digitales. El profesional de la información, 24(4), pp. 390-395.

Yanke, R. (2 de enero de 2015). "Es ridículo. Un menor mata a otro y no se le puede tocar". El Mundo. Recuperado de http://www.elmundo.es/espana/2015/01/02/54a 58e0a22601d36278b4574.html

VV. AA. (2016). Constitución Española. Madrid: Tecnos.

Willard, N. (2007). Cyberbullying and cyberthreats. Responding to the challenge of online social aggression, threats and distress. Illinois: Research Press. 